\title{
Applied Technology in Excel Model Design on Decisions of Additional Order at A Special Price
}

\author{
Jintao Liu ${ }^{1, \text { a }}$, Li Sun ${ }^{2, b}$, Zhenzhen Sha ${ }^{3, \mathrm{c}}$ \\ ${ }^{1}$ (QingDao Vocational and Technical College of Hotel Management, Qingdao, China) \\ ${ }^{2}$ (QingDao Vocational and Technical College of Hotel Management, Qingdao, China) \\ ${ }^{3}$ (QingDao Vocational and Technical College of Hotel Management, Qingdao, China) \\ aliujintaoqd@163.com, ${ }^{\text {b }}$ sunli5363@126.com, ${ }^{\mathrm{c}}$ shazhenzhen1984@163.com
}

\begin{abstract}
Keywords: Excel Model,Special Price,Additional Order,Spare Production Capacity,Decision, XBRL
\end{abstract}

\begin{abstract}
Decisions of additional order at a special price are common problems on daily production operations, but as a result of the various specific situations, the decision-making is more difficult. This paper analyzes four different additional order scenarios under special prices, uses function and formula in the Excel to design appropriate model, and puts forward combined with XBRL and excel, to simplify the decision- making process and improve the efficiency and accuracy of decision-making.
\end{abstract}

\section{Introduction}

Making production decisions is an important part of management accounting decision-making functions, and it is also an important part of enterprise short-term business decisions. Production decisions are mainly revolves around the production, what will be produced, how to product, and what the extent of the production is as well as how many to product, including such content: production decisions about which products to develop ,new product varieties decision , decisions of how to get the parts and accessories, decision-making of additional order at a special prices, the degree of product processing decisions, loss products' decision-making on discontinuation or conversion. The basic analysis methods of production decisions in three ways: the contribution margin, differential analysis, cost balance point method. In making decisions on specific production problems, it needs to use basic analysis method according to the specific situation flexibly. In the decision process of production, special price for an additional order decision belongs to one of the more complex decision type. This paper analyses this decision, and uses the excel model, to simplify the decision making.

\section{Organization of the Text}

\section{Theory of Additional Order Decision At Special Prices}

Special prices refers to the price of this order is lower than it of the normal sale, even lower than the unit cost of the product price. Special Price Added ordering decisions refers such a behavior that when the enterprises still have some spare production capacity, while other companies require additional orders at lower prices, the companies decide whether to accept this additional order. ${ }^{[1]}$ Special Price additional order (hereinafter referred to as: special order) decisions facing the situation can be divided into four kinds; four scenarios corresponding to different solutions, the details are as follows:

Scenario 1: Special order quantity is less than or equal to the spare production capacity, and spare production capacity can not be transferred.

In such situations, if additional orders will not increase the cost of proprietary, the order will not affect the existing normal sales, as long as : special order product price changes is greater than the unit cost of the product, that is a special order unit contribution margin is greater than zero, you 
can choose to accept orders. If you need to add specific additional costs orders, the order will not affect the original normal sales, as long as : the total contribution margin is greater than the private cost of special orders, that is the remaining total contribution margin is greater than zero that is special order, you can choose to accept orders.

Summary: (unit price of special order - unit variable cost) ×special order quantity- exclusive costs $>0$, choose to accept the order. On the other hand, does not accept the order. When the exclusive cost does not occur, exclusive cost in the above formula is 0 .

Scenario 2: Special orders' quality is greater than the spare production capacity, accepting orders will reduce part of the normal order of sales, and the spare production capacity can not be transferred.

In this context, Contribution margin loss caused by accepting the order and reducing normal sales is looked as an opportunity cost to accepting the additional order. If ordering additional does not increase exclusive costs, as long as the total contribution margin is greater than the marginal contribution loss caused by accepting the order and reducing normal sales, you can choose to accept orders. If it needs to add additional costs of ordering, the remaining total contribution margin of the special order is greater than the amount of the contribution margin due to reduced sales and loss of normal, the company can accept orders.

Summary: (unit price of special order - unit variable cost ) $\times$ special order quantity - the exclusive cost $>$ Contribution margin loss caused by accepting the order and reducing normal sales , then choose to accept the order, on the contrary, refusing to accept special orders . When the exclusive cost does not occur, exclusive cost in the above formula is 0 .

Scenario 3: Special order quantity is less than or equal to the spare production capacity, and the spare production capacity can not be transferred.

When the spare capacity can be transferred, the benefits brought by transferring production capacity is considered as an opportunity cost of the additional order .Combining the analysis of scenario1, we can get, if additional order does not increase the exclusive cost , as long as the total contribution margin from special orders is greater than the opportunity cost ,then accept the special orders ; If additional orders need to increase exclusive costs, then the total remaining contribution margin from special orders is greater than the opportunity cost, then to choose accepting the special orders .

Summary: (unit price of special order - unit variable cost) $\times$ special order quantity- exclusive costs $>$ opportunity cost, choose to accept orders. On the other hand, does not accept the order. When the exclusive cost does not occur, exclusive cost in the above formula is 0 .

Scenario 4: Special order quantity is greater than the spare production capacity , accepting this order will reduce part of the normal order sales, and the spare production capacity can be transferred.

Combining with analysis of Scenario 2 and Scenario 3, you can get, in this situation, if the additional order does not increase the exclusive cost, as long as the margin contribution of the special order is greater than the total amount of the opportunity cost and the marginal contribution caused by accepting the order as well as losing normal sales, you can choose to accept orders. If accepting additional orders will add exclusive cost, as long as the margin contribution of the special order is greater than the sum of the opportunity cost and the remaining marginal contribution caused by accepting the order and reducing normal sales, then to accept orders.

Summary: (unit price of the special order - unit variable cost ) $\times$ special order quantity - exclusive cost $>$ the total amount of the opportunity cost and the marginal contribution caused by accepting the order as well as losing normal sales, then choose to accept orders, on the contrary , refuse to accept special orders. When the exclusive cost does not occur, exclusive cost in the above formula is 0 .

By Analyzing these four scenarios, we can see the special price of ordering additional decision's analysis process is more complex, especially the four scenarios. Therefore, we can build the model by the help of Excel to improve the efficiency of decision making. 


\section{Designing and Applying Excel Model of Decisions of Additional Order At A Special Price}

In this paper, the author quotes one example in the < Management Accounting>, edited by Subin Wen and duplicated by Dongbei University of Finance and Economics Press in 2010, the example is in the page of $88^{\text {th }}$ and $89^{\text {th }}$, which is [Example 5-9 ], [ Example 5-10 ], [Example 5-11 ]and [Example 5-12 ], the author tries to create Excel model based on this example. The example is summarized as follows:

A company produces a product, the maximum production capacity is 1,200 units , the normal sales are 1,000 units, the spare production capacity is 200 units, the normal unit price is 1000 Yuan , total fixed cost is 300,000 Yuan , unit variable cost is 600 Yuan. The highest unit bid of existing customer orders is 800 Yuan.

(a ) If the existing customer orders 200 units, please answer whether to accept the order or not ?

( b ) If the quantity of the special order is 500 units, receiving this order needs to reduce 300 units with the normal price, then, please answer ,how much the price of the special order is in order to increase profits of the enterprise the business?

( c ) Assuming a special order quantity is 200 units, accepting this special order needs to lease a piece of equipment from outside the enterprise, the annual rent is 30,000 Yuan , please answer, whether the enterprise should accept this special order or not?

( d ) Assuming a special order quantity is 200 units, accepting this special order needs to lease a piece of equipment from outside the enterprise, the annual rent is 30,000 Yuan ,on the contrary ,the company can refuse the special order, and rent out the spare production capacity, in this way, the company can get an annual rent of 20,000 Yuan, ,please answer, whether it should receive additional orders or not? ${ }^{[2]}$

For the above example, the Excel model should be resigned as table 1 :

Table 1 Excel model on decisions of additional order at a special price

\begin{tabular}{|c|c|c|}
\hline & A & B \\
\hline 1 & Item & \\
\hline 2 & The Maximum Production Capacity & 1200 \\
\hline 3 & Normal Sales & 1000 \\
\hline 4 & Normal Sales Price & 1000 \\
\hline 5 & Unit Variable Cost & 600 \\
\hline 6 & Special Order Quantity & \\
\hline 7 & Unit Price of The Special Order & \\
\hline 8 & Exclusive Cost & \\
\hline 9 & Opportunity Cost & \\
\hline 10 & Final Decision: & $\begin{array}{l}=\mathrm{IF}((\mathrm{B} 7-\mathrm{B} 5) * \mathrm{~B} 6-\mathrm{B} 8>\mathrm{B} 9+(\mathrm{IF}(\mathrm{B} 6>(\mathrm{B} 2- \\
\mathrm{B} 3),(\mathrm{B} 6-(\mathrm{B} 2-\mathrm{B} 3)) * \mathrm{~B} 4,0)), \text {, accept the } \\
\text { order","refuse the order") }\end{array}$ \\
\hline
\end{tabular}

In this model, one function formula should be applied, it's IF. This function's grammar is: IF(logical_test,value_if_true,value_if_false)

The enterprise's original production and sales data is entered in A2: B5 area. In A6: B9 region, it is a special order price additional data, different additional orders are truthfully entered according to the specific scenarios. Region A10: B10 is the decision region, and it's also the key point of this model, input " =IF((B7-B5)*B6-B8>B9+(IF(B6>(B2-B3),(B6-(B2-B3))*B4,0)), "accept the order", "refuse the order")

In the above example, Q ( a ), enter 200 in cell B6 and 800 in B7 ,in cell B8 and B9, you can input 0 , or do not enter any value, keep it null. In this scenario, the Cell B10 will display " accept the order."

Q (b) , in the model above, enter 500 in cell B6 and 800 in B7, the same way, you can input 0 , 
or do not enter any value, keep it null. In this scenario, the Cell B10 will automatically display " refuse the order ."

Q ( c) , in the model above ,enter 200 in cell B6 and 800 in B7, enter 30000 in cell B8, you can input 0 , or do not enter any value, keep it null. In this scenario, the Cell B10 will automatically display " accept the order ."

Q ( 4 ), in the model above, enter 200 in cell B6 and 800 in B7, enter 30000 in cell B8, enter 20000 in cell B9 . In this scenario, it will automatically display the conclusion:" refuse the order ." in Cell B10.

Enterprises can input data in this excel model according to the specific circumstances of the additional order, and it can quickly get decisions conclusions.

As a model, it should be universal and safety. So, in order to ensure this model safe, and that the users cannot change the data in the model, but only can input data in area B6:B9, this model can be protected. Select the B6:B9, set the cell format, in the "protection" tab, remove the check mark on the front of the "lock" button. The purpose of doing it is in the worksheet protection, value of these cells can still be changed. Select "tools" menu under the protection work table submenu, bring up dialog box of the protection Work Table. Click the OK button, working table can be protected. The sheet protection, users can input the data in the B6:B9 area, while the other cells can not be modified. Designers can also set the password protection, after setting a password; you can lift the sheet protection, only in the correct password.

XBRL technology's application, adds labels to all the documents of the enterprise business, this label is unique, so these "data elements "with labels, can be obtained quickly and accurately. After the purchasers offer the purchase price of the order, it should form the data in the system, now the XBRL are embedded in the excel, so it can realize both cohesion. Now, Xinba developed by Japan's Hitachi company and Office Tool for XBRL Prototype developed by Microsoft software are XBRL financial analysis software plug-ined in Excel, these can be downloaded from the Internet through Web Service mechanism instance documents for automated financial analysis. The latter can be used as a free download.

\section{Conclusion}

Whether or not to accept the special price of additional ordering is a common problem of enterprise in daily production management, in the face of a specific situation, the theoretical methods the enterprises can use are not the same .on the basis of analyzing the theory and using Excel and XBRL, the enterprise can design the appropriate model, it will help to respond to specific situations flexibly, make decisions quickly, improve decision-making efficiently.

\section{References}

[1] Lin Hui . Additional order special pricing decisions and business outcomes. Finance and Accounting Monthly .2009.5(In Chinese)

[2] Subin Wen. Managerial accounting. Dongbei University of Finance and Economics Press .2010.1(In Chinese) 